\title{
USE OF INTERNATIONAL CLASSIFICATION OF FUNCTIONING, DISABILITY AND HEALTH (ICF) CORE SET FOR PATIENTS WITH ISCHEMIC HEART DISEASE (IHD)
}

Gintarè NARMONTAITĖ, Alvydas JUOCEVIČIUS.

Centre of Rehabilitation, physical and sport medicine, Vilnius University Hospital Santariskes Clinics, Lithuania

\section{Introduction}

IHD affects individuals quality of life by disrupting the future of families dependant on them and undermining the development of nations by depriving valuable human resources on their productive years. The international classification of functioning, disability and health Core Set for IHD (ICF), that reflects the biopsychosocial model is a wide instrument for evaluating effectiveness of rehabilitation for patients with IHD. It covers all aspects of patient functioning.

\section{Purpose}

To examine relationships among heart ultrasound, veloergometry with and categories of the Brief Core Set for IHD and determine which ICF categories are most relevant for patients with IHD.

\section{Methods}

A prospective study including 110 patients with verified IHD who were enrolled during the first two days of rehabilitation after coronary artery bypass surgery $(40 \%)$ or percutaneous coronary intervention $(60 \%)$ were evaluated of the Brief Core Set for IHD. Patients were interviewed at the end of the rehabilitation treatment - lasting on average three weeks and after six months after their discharge. Statistical analyses of relationships between ICF categories as independent variables and results of the heart ultrasound or veloergometry were carried out by simple and stepwise linear regression models adjusting for age, sex, and occupation.

Improvement

$\%$

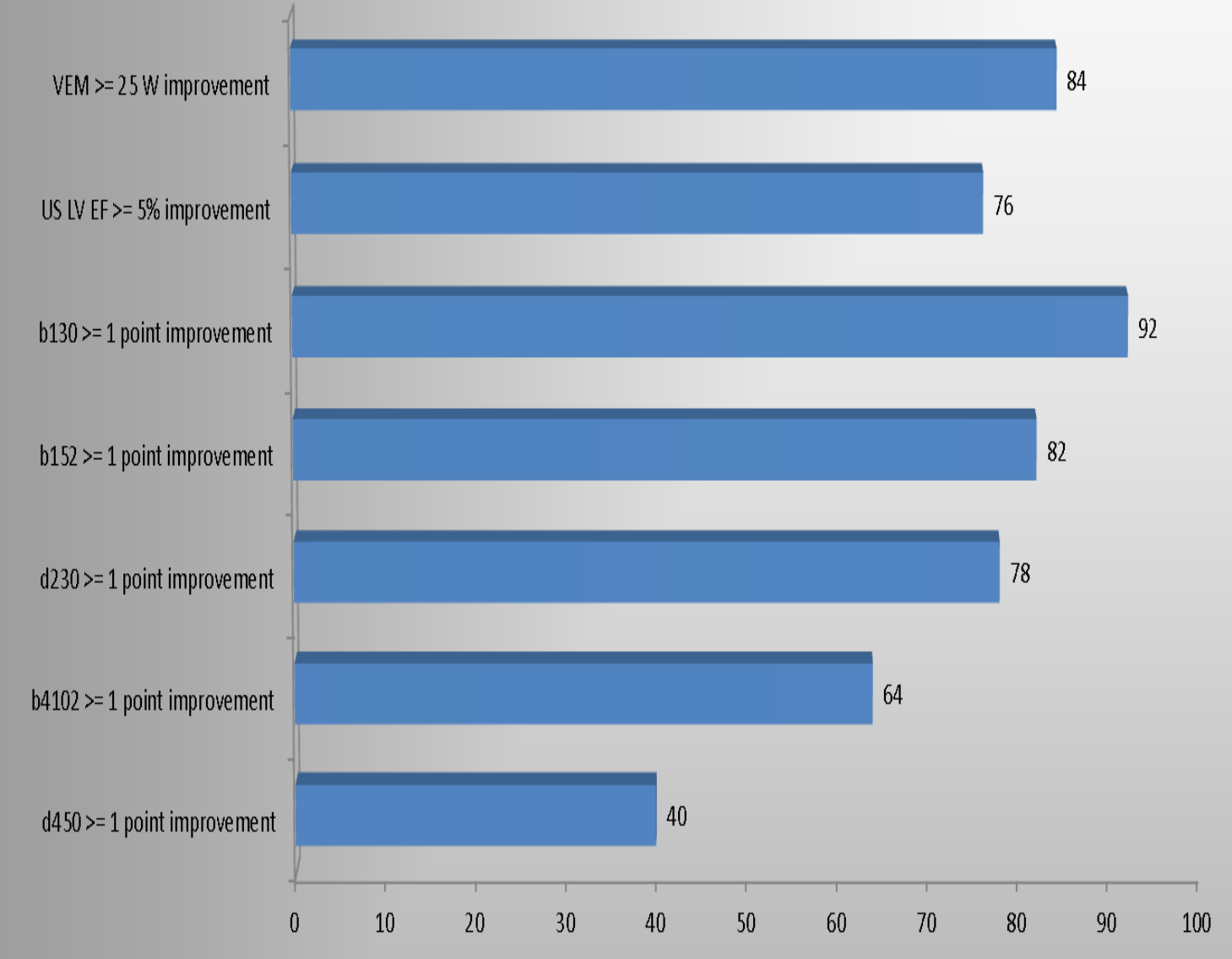

\section{Results}

The statistical analysis of relationship between ICF and heart ultrasound or veloergometry change (improvement) was performed with the chi-square test and logistic regression models, adjusting for age, sex and occupation.

Calculating a stepwise linear regression model with veloergometry as dependent variable, a significant effect of age, emotional functions, energy and drive functions, carrying out daily routine, as well as walking could be observed.

A significant relationship was found between US improvement $(>=5 \%)$ and age (age EF < 5: 57,8 $\pm 6,9$; age EF >= 5: 68,3 \pm 7,4; $\mathrm{p}<0,001)$ and ICF improvement ( $>=1$ point) (b130, d230, d450, b4102).

The stepwise linear regression model with heart ultrasound as dependent variable revealed a significant effect of the variables blood vessel functions and muscle endurance functions.
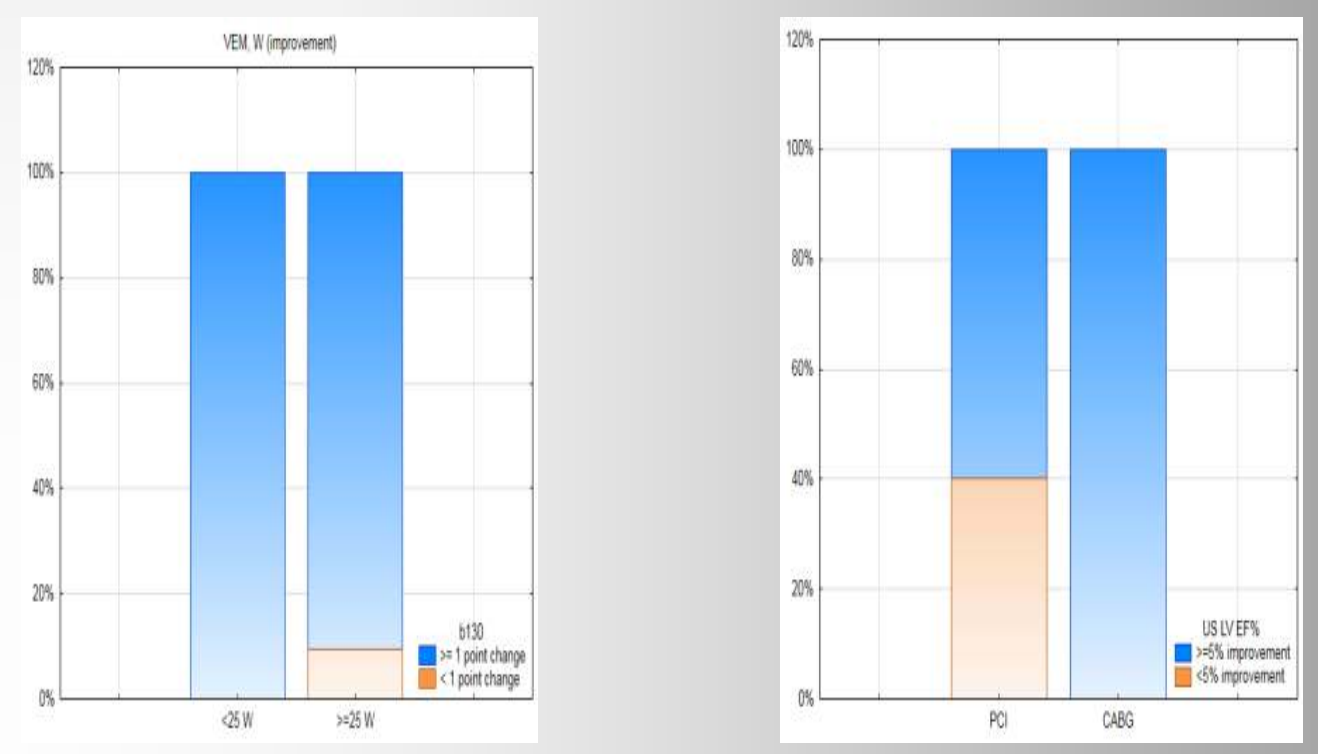

\section{Conclusions}

This study establish that Brief Core Set for IHD shows a significant correlation on heart ultrasound and veloergometry in patients with IHD. ICF application in patients with IHD enables to enlarge perspective on their health status, and provide fundamental information to follow the healthcare process from the in-patient period to the outpatient management.

\section{References}

Mozaffarian D et al. Heart disease and stroke statistics- 2015 update: a report from the AHA. Circulation. 2015;131(4):322.

Raevschi E., The ICF- a new conceptual framework of medical rehabilitation. Acta Medica Transilvanica. 2011;16(3):264-265.

Rauch A, Cieza A, Stucki G. How to apply ICF for rehabilitation management in clinical practice. Eur J Phys Rehabil Med.

2008;44:329.

Grill E; Quittan M et al. Brief ICF Core Sets for the Acute Hospital. Journal of Rehabilitation Medicine. 2011;43(2):123. 